\title{
Touch and surgical division of the anterior quadrant of the spinal cord
}

\author{
P W Nathan *
}

\begin{abstract}
An investigation was carried out to determine whether tactile sensibility was affected by anterolateral cordotomy. There were 65 patients who had cordotomies for painful forms of cancer. Thirty eight had necropsy examination with histological investigation of the spinal cord. No form of mechanoreception was removed in any of the 65 patients and in the majority no forms of tactile sensibility were altered by division of the pathways in the anterolateral and anterior columns. In no case was graphaesthesia affected. Knowledge of joint position and movement and awareness of vibration was normal in 62 of the 65 patients. But information carried by these anterolateral pathways does reach neural levels of consciousness, for with total lesions of the posterior columns, previously reported, touch and pressure are still felt. Itch was removed by division of the anterolateral pathways. Although the posterior columns are essential for discrimination in mechanoreception, discrimination may be disturbed by lesions of the anterolateral pathways, notably two-point discrimination. The evidence on the pathways essential for conveying impulses giving rise to tickle was inconclusive.
\end{abstract}

*The material for this study was collected when the author was a member of the External Scientific Stafi Medical Research Council.

The study of lesions of the spinal cord to determine the pathways conveying sensory information to the brain began at the end of the nineteenth century. At the onset of the First World War, it had been established that tactile sensibility depended on two routes, an uncrossed pathway in the posterior columns and a crossed pathway in the anterior or anterolateral columns. The evidence showed tained from war injuries, concluded that with aspect of mechanoreception could be served by a crossed pathway in the anterior quadrant of the cord.

The subject of these two pathways conveying various forms of sensory information to the brain was re-examined by Nathan et al. ${ }^{5}$ The main question considered in that paper was the kind of change in sensibility that occurred with lesions of the posterior columns. In this paper, the question of changes in mechanoreception with lesions of the crossed anterior and anterolateral pathways is considered. Within the last few years it has been learned that descending tracts from the brain play a role in sensibility. So many inhibitory centres in the brain have been found in experiments in rats and cats that we have un embarras de richesse; fortunately there are some facilitatory pathways as well. What role these centres play in normal sensibility, in states of acute and chronic injury, and pain, and in the psychological aspects of tests in sensibility, we do not yet know. Head and his colleagues questioned what the cerebral cortex makes of the information it receives when either the afferent pathways of the posterior columns or the anterolateral columns were divided. This is still a suitable question, even though we must now add to it that various descending pathways may be playing a role.

\section{Material}

There were 65 patients with painful forms of cancer; the number of patients, sex, and diagnoses are shown in the table. Of the patients who had necropsy examination, the duration of survival after anterior or anterolateral cor-

Table Characteristics of patients

\begin{tabular}{lrrr}
\hline Diagnosis & Number & Sex & \\
\hline $\begin{array}{l}\text { Carcinoma of cervix } \\
\text { of uterus }\end{array}$ & 23 & $23 \mathrm{~F}$ & \\
$\begin{array}{l}\text { Carcinoma of body } \\
\text { of uterus }\end{array}$ & 3 & $3 \mathrm{~F}$ & \\
$\begin{array}{l}\text { Carcinoma of bronchus } \\
\text { Carcinoma of rectum }\end{array}$ & 12 & $2 \mathrm{~F}$ & $10 \mathrm{M}$ \\
Carcinoma of colon & 5 & $1 \mathrm{~F}$ & $6 \mathrm{M}$ \\
Carcinoma of bladder & 6 & $1 \mathrm{~F}$ & $4 \mathrm{M}$ \\
$\begin{array}{l}\text { Metastasis in Os } \\
\quad \text { Innominatum }\end{array}$ & 2 & & $4 \mathrm{~F}$ \\
$\begin{array}{l}\text { Chondrosarcoma of ilium } \\
\text { Diffuse carcinomatosis }\end{array} \quad 2$ & & $2 \mathrm{M}$ \\
$\quad$ from carcinoma of breast & 1 & $1 \mathrm{~F}$ & \\
$\begin{array}{l}\text { Carcinoma of anal canal } \\
\text { Melanoma }\end{array}$ & 1 & 1 & \\
Carcinoma of ovary & 1 & $1 \mathrm{~F}$ & \\
Carcinoma of Bartholin's & 1 & $1 \mathrm{~F}$ & \\
$\quad$ gland & 1 & F & \\
$\quad$ Total & 65 & $37 \mathrm{~F}$ & $28 \mathrm{M}$ \\
\hline
\end{tabular}
that touch and pressure were still felt when either of these pathways had been divided. What aspects of tactile sensibility were disturbed by division of the crossed pathway in the cord was not clearly stated by Head and Thompson, ${ }^{1}$ Head and Holmes ${ }^{2}$ nor Head. ${ }^{3}$ Head ${ }^{4}$ however, with further evidence obposterior column lesions, "spot-finding" or the ability to appreciate the spot touched was still normal and so he considered that this revised form July 1989 and

1989.

Accepted 6 March 1990
National Hospital for Queen Square, London, United P W Nathan

Correspondence to: Dr Nathan, National Hospita Queen Square, Lond WCIN 3BG, United Kingdom. 
dotomy was between 24 and 240 days. All the cordotomies were done by open surgical operation and the lesions were made by scalpel. This surgery results in clearcut lesions, as are seen histologically. Lesions made by thermocoagulation in percutaneous operations provide less definite lesions and often several lesions are made. One of the advantages of using cordotomies for this study is that there is a large variety of lesions, extending between the anteromedian fissure and just posterior to the denticulate ligament. And further, these operations were performed at every segment of the spinal cord, the highest being in the lower medulla and the lowest in the Ll segment. In 11, the operation was done in the cervical cord, and so the sensory examinations were carried out in the upper as well as the lower limbs. Seventeen patients having a unilateral operation and 21 having a bilateral operation had necropsy examination with histological study of the nervous system. Six cases with bilateral and 21 with unilateral cordotomies had no necropsy examination. The different proportion of unilateral to bilateral operations that do not have a post mortem needs a comment. The defects due to a bilateral operation were more likely to cause the patient to remain in hospital until death, when a post mortem could be obtained, whereas patients with a unilateral operation had few defects and returned home.

Degeneration in the posterior columns was seen in many cases, but it was always due to the continuation of posterior nerve roots within the columns that had been involved in the cancer or that had been therapeutically destroyed to relieve pain. The areas supplied by these nerve roots were not examined in detail and no observations on them are mentioned here.

\section{Methods}

Most patients were admitted to hospital for three to four weeks before the operation. During this time, sensory testing was carried out on many occasions. After the operation, sensory testing was resumed usually within two or three days of the operation. Sensory testing ceased when the patient returned home. This time varied; for instance the patient whose spinal cord is illustrated in the figure, returned home six weeks after the operation. He died 121 days later. When he was in hospital

Figure Bilateral anterolateral cordotomy at T 9 segment Marchi preparation. Bar $=1 \mathrm{~mm}$. some tests were carried out almost every day. As the patient's condition deteriorated testing was stopped. Not all the tests were carried out on every patient but in each patient the same tests were repeated before and after the operation. This paper is concerned with the examination of mechanoreception and not with other aspects of the operation of cordotomy; these have already been published.

The following examinations were carried out:

1) Awareness of any sensation when a hair or hairs of the skin on the limbs were moved.

2) Repeated touches with cottonwool.

3) Von Frey hairs. These were numbered as von Frey recommended according to what he preferred to call "tension" ( $t$ ). As force includes the square of the radius of the hair, the figures become unduly large and apparently distorted; and so von Frey recommended the use of a more linear figure, obtained by dividing the bending force in $\mathrm{mg}$ by the radius of the hair. This was measured by a micrometer screwgauge. The tensions of the hairs applied were from 0.85 (Nylon 1) to 31 . Tensions of eight and above should be classified as touch + pressure. Some equivalents in $\mathrm{g}$ are t $3.6=0.4 \mathrm{~g}$ (Nylon 3), $\mathrm{t} 7.5=0.75 \mathrm{~g}$. The Nylon 1 hair was applied as a single stimulus vertical to the skin and it was also dragged along the skin. As a single stimulus it is at threshold in most places, though in some areas of skin it is below threshold. As a dragged stimulus it is just above threshold. Areas of $1 \mathrm{~cm}^{2}$ were marked in ink in many areas of the body, and the number of tactile stimuli felt was noted. With hairs of most tensions, there was no limit to the number felt within an area; with hairs of small tension, it was more than 10. In this and all other quantitative tests, the patients were questioned about the quality of the sensation and specifically asked about any differences between the area affected by the cordotomy and other areas.

4) A purely tactile stimulus that did not indent the skin consisted of a spark delivered 1 to $2 \mathrm{~mm}$ from the skin surface. With a slight current, this caused a tactile sensation; with increased current, it caused pricking pain. That a minimal electric stimulus causes touch and not pain was already known to Goldscheider. ${ }^{6}$

5) Graphaesthesia.

6) Rubbing the skin with the examiner's finger.

7) Light pressure on the skin was tested by a tonometer designed for testing ocular pressure. The stimulus was a circular disc, $0.3 \mathrm{~mm}$ diam. It was left on the skin for a few seconds, the pressure increasing. This was not a very satisfactory test as nearly all patients reported that they felt the stimulus as soon as it touched the skin.

8) For two-point discrimination, the usual compass test was applied; in fact, the instrument used was the one previously used by Head and Holmes.

9) Knowledge of movement and joint position of terminal digits. 
10) Sensation of vibration; forks of 256 and $512 \mathrm{~Hz}$ frequency were applied over bone.

11) Tickle. This was examined by stroking the skin, usually of the abdominal walls, with a wisp of cottonwool; and by firmly stroking the sole of the foot in eliciting the plantar response.

These tests are of two kinds: a basic test requiring a yes or no answer, which simply asks the person if they know whether they have been stimulated; and a test of higher level functions, such as judgement, exemplified by the two-point discrimination test.

No reports of painful and thermal sensibility are included in this paper.

\section{Results}

The figure shows the largest extent of a bilateral cordotomy that divided the anterior half of the cord. All modalities of sensibility were normal after this operation: single hair moving, figure-writing, two-point discrimination were normal; the von Frey hair $0.4 \mathrm{~g}$ (Nylon 3) was felt quantitatively and qualitatively identically above and below the level of the cordotomy; the tickle induced by cottonwool was also felt normally. The reason for showing this example is to make it clear that mechanoreception can be normal with all the ascending and descending tracts of the anterior half of the cord divided.

The results of all the patients are as follows:

Stroking with cottonwool The tactile sensation on being stroked with cottonwool was normal in 62 of the 65 patients. In the three in whom it was affected, one patient said it felt less distinct, one said "it was more sensitive" and one said it felt different but she could not explain in what way.

Rubbing with the examiner's finger In 35 of the 65 patients no change was noted. In 12, there was a definite difference in the sensation between the areas affected by the cordotomy and normal area. In two, it felt tingling, in two it felt "numb" or "dead", in one it was unpleasant, and in seven it felt different, often causing less sensation.

Moving hairs on the patient's limbs Moving one hair was felt in 64 of the 65 patients.

Graphaesthesia In no patient was graphaesthesia altered or impaired.

Touch and pressure tested by von Frey hairs In 50 of the 65 patients tested there was no difference between the region affected by the cordotomy and normally innervated regions; in 15 there was some difference. Thus $77 \%$ had no change in tactile sensibility, examined by von Frey hairs. In seven of those patients who noted a difference, they commented that the hair felt lighter or diminished; in two there was a decreased number felt per unit area of the lightest hairs, though when the hairs were felt, there was no change in threshold. These differences did not apply to ten- sions of eight or above, in which pressure rather than touch is the sensation. In four the hairs were felt more clearly than in a normally innervated area. In one the sharp element was absent in the area affected by the cordotomy, and in one the hairs gave a tingling sensation.

Two-point discrimination Two-point discrimination was normal in 58 of the 65 patients. In one patient it was improved in the area affected by the cordotomy. In three it was slightly worse than before the operation. In two patients, a single stimulus felt like two. In one patient it was diminished for 10-15 days after the operation, and then recovered. One patient said that after the operation he obtained so little information that he felt he was guessing. It felt blunter than on the normal side, having lost any element of sharpness; and single stimuli felt larger than on the normal side.

Sense of position, movement and vibration Awareness of movement and position of the digits and sensation of vibration were normal in 62 of the 65 patients. In the three patients in whom these forms of sensibility were affected, vibration was not felt and sense of movement and position was deficient in two; in one patient these forms of sensibility were decreased for one month after the operation and then started to recover, eventually becoming normal. A second cordotomy on the other side of the cord had no effect on these forms of sensibility on either side.

Tickle In the majority of patients, the sensation of tickle, both on the skin of the abdomen elicited by a wisp of cottonwool and on the plantar surface elicited by a heavy stroke, was unaffected. In nine patients tickle on the abdominal skin was absent. In four patients in whom abdominal skin tickle was absent, plantar tickle to a firm stroke was present but diminished. In four patients plantar tickle was absent and in six diminished. In one patient abdominal skin tickle was absent but plantar tickle was present. One patient found that tickle on the abdomen was very different from on the normal side. It caused more tickle and the patient would laugh on being tested. It felt different in that it felt as though it were deep to and not on the skin. He had this sensation also from having tight clothes, from pinprick, from a dragged pin and touch or pressure on the skin.

Other sensory features In some patients in whom there was already some loss of sensibility due to involvement of peripheral nerves or nerve roots in the cancer, this diminution was increased after the operation.

In five patients a cordotomy was done first on one side and later on the opposite side. In none of these patients was there any change in these forms of sensibility after the second cordotomy on the side of the body opposite the first cordotomy. 


\section{Discussion}

With the anterior and anterolateral columns divided, the various kinds of sensation classifiable as mechanoreception are entirely normal in the majority of subjects. A case such as the one of which the cord is illustrated in the figure is good evidence that essential pathways for mechanoreception and tickle are elsewhere. However, the pathways of the anterior and anterolateral columns do convey information about mechanoreceptor input to the brain; for with total lesions of the posterior columns, touch and pressure are still felt. In a previous paper ${ }^{5}$ in which the evidence was collected on the effects of lesions of the posterior half of the cord, it was concluded that the posterolateral columns did not normally contribute to sensation. With the posterior columns, it was concluded that with lesions of this afferent pathway, "Primary sensibility for light touch and pressure is not lost, but any kind of discrimination is disturbed. There is also a disturbance of knowledge of movement and position, ataxia, and clumsiness in the use of the hands". Provided the posterior columns are functioning, the most delicate tests for tactile sensibility such as moving one hair of the patient's leg or arm, are normal. As the posterior columns are essential for discrimination, it was expected that discriminatory kinds of sensibility would be unaffected by lesions of the pathways in the anterior and anterolateral columns. In fact in none of the patients was graphaesthesis altered but two-point discrimination was affected in eight of the 65 patients.

Itch is removed by division of the anterior and anterolateral columns. But tickle, both tickle induced by a light minimal dragging stimulus on the skin and firm stroking of the plantar surface of the foot, was not affected in the majority of patients.

Of the kinds of sensibility examined here, tickle is the least purely sensory. The emotional aspect is obvious; and it depends more than other forms of sensibility on the location of the stimulus. A firm moving stimulus along the plantar surface may cause tickle whereas the identical stimulation on the sternum gives rise to pressure and perhaps pain. The lightest touch on the muco-cutaneous junction of the lip can cause tickle whereas elsewhere it causes only a tactile sensation. Faced with such a nonunitary kind of sensation, one should not have any a priori belief of how tickle might be affected by a lesion of any pathway.

There is inadequate evidence in the literature on how tickle is affected by lesions of the posterior columns. But with acute lesions of the posterior columns, painful stimuli become even more painful and mechanical stimulation that is not normally painful becomes very painful. There is a similar increase in cold, and warmth. This was first described by Foerster. ${ }^{8}$ It was discussed by my colleagues and myself in a previous paper, ${ }^{5}$ and tickle was added to the list.

A patient was seen in whom there was every reason to believe that a spinal tumour involved only the posterior columns. This patient could hardly feel the tactile element of light touches with cottonwool in both lower limbs but on the right it caused a marked tickle. It was noticeable how quickly and well she localised the stimulus on the right compared with the left; the patient said she did this entirely on account of the tickle. In the right limb, water at $27^{\circ}$ felt very cold whereas it only had a slight sensation of cold on the left, and ice felt abnormally cold. Hot stimuli were more painful on the right.

As sensations of warmth, cold and pain depend on the anterolateral pathway, one would have thought that tickle, in this case, also depended on this pathway. But in our results reported above, tickle was not disturbed by anterolateral cordotomy.

No reference is made here to the vast literature on cutaneous and deep sensibility in humans. But it is rewarding to compare the results reported here with those of the other large series of adequate cordotomies reported by White and Sweet. ${ }^{7}$ They also found that the threshold to touch was unaltered in some patients and slightly increased in the majority. In the majority of our patients tactile threshold was unaltered. In their patients, position sense was normal; this was so in 62 of our 65 patients. In their patients, vibration was "never more than minimally reduced". In two of our patients, it was affected, later becoming normal in one; in all the others it was normal. They found that tickle on the sole was often reduced but not removed. The patients reported here judged that tickle was the same after as before the operation. In both series, itch, when it could be examined, was removed.

With regard to the sensory examination, it is clear that two people with the same lesion do not necessarily report the same sensations. One factor is the relation between what the patient expects to feel and any actual perception of stimuli. Further, when one examines sensation, one notes that there are those patients who notice nothing and those who notice minutiae. And further, patients learn as sensory examination proceeds. There is also the factor of the patient's ability to communicate.

That sensibility may be actually improved by a division of some afferent nerve fibres, provided constant pain is removed, has been noted before. ${ }^{9}$ This also occurred occasionally in this group of patients.

If impulses arising from the mechanoreceptor input were running on the side opposite the cordotomy incision, then a bilateral cordotomy would be expected to have more defects in sensibility than a unilateral one. This did not occur. There was also no change in sensibility after a second cordotomy was carried out on the side opposite the first operation. Thus there is no evidence that impulses were being re-routed along the other side of the cord after the first cordotomy. Incidentally, this also applies to warmth, cold and pain.

Evidence of the location of lesions upsetting the sensation of vibration was collected by Calne and Pallis. ${ }^{10}$ In reviewing the literature, they found, as we did when we examined the literature on posterior column lesions, that pure lesions of the posterior columns were very 
rare and many previous conclusions were not justified. They concluded that the relevant impulses ran in the posterior columns and probably also with the lateral corticospinal tracts, deep in the posterolateral columns. Our evidence supports their conclusion concerning the anterior columns. In the patients reported here with lesions of the anterior quadrant of the cord, sense of position and movement and of vibration were normal, although in three of the 65 patients, this was not so.

Lockard and Kempe ${ }^{11}$ have recently published evidence that "the traditionally accepted pathways for position sense, vibratory sense and tactile discrimination for the lower and upper extremities are still valid"'. They reported five unusual cases of selective damage to the posterior columns, which was due to stab wounds, trauma from a comminuted fracture, or an arteriovenous malformation. These patients had a loss of position and vibratory sense and tactile discrimination.

In spite of the evidence collected and presented here, no consideration of afferent pathways in the cord is adequate if it does not include the two cases of stab wounds of the spinal cord published by Noordenbos and Wall ${ }^{12}$ and Wall and Noordenbos. ${ }^{13}$ These stab wounds divided a very large area of the spinal cord. In both cases, there were transections of the posterior columns, the posterolateral columns, most of the gray matter and a considerable part of the anterior and lateral column of one side of the cord. In both these patients tactile sensibility was present on both sides of the body below the lesion. The first patient had remarkably good knowledge of passive movement of the knee on the side of the body corresponding to the remaining anterolateral column of the cord. The second patient probably had more tissue remaining in the cord than the first. Knowledge of passive movement of the knee was present, though impaired, bilaterally. Vibration was not felt in the first patient but was felt in the second on the side of the remaining anterior column.

One difference between patients with posterior column lesions and the two cases reported by Wall and Noordenbos is that with lesions of the posterior columns, the sense of movement and position is impaired when fine movement of the digits are tested and more impaired when the hands, feet and digits are used for manipulation. Gross movements such as those of the knee are felt normally when the subject pays attention to them. In South Africa, where stabbing between the vertebral spines is practised, the syndrome due to division of the posterior columns is seen. One hundred and thirty stab wounds of the spinal cord have been briefly reported by Lipschitz and Block ${ }^{14}$ and 450 by Peacock et al. ${ }^{15}$ Martin $^{16}$ saw the significance of stab wounds likely to damage the posterior columns selectively and published details and a photograph of one of the patients of Lipschitz and Block. In this patient and some of the others there was total loss of position sense. The presumed functioning of the anterolateral columns does not compensate for this deficiency.

It is concluded from the evidence presented in this paper that a patient with a lesion dividing the anterior and anterolateral columns may have no defects of mechanoreception. And further, even in those patients in whom sensory examination demonstrates some defects, these defects are often unnoticed by the paient in the usual activities of living.

This study and those of my colleagues support the traditional beliefs of clinical neurology. With lesions of the posterior columns pressure and touch are felt, but any kind of discrimination is disturbed. There are marked defects in knowledge of position and movement. There is clumsiness of the hands and ataxia. These disturbances are much more marked during the activities of living than they are in the neurological examination. With lesions of the anterior and anterolateral columns there may be no, or slight defects, in mechanoreception. These disturbances do not affect the activities of living, though they may be detected in the neurological examination. When there is a lesion of the posterior and the anterior and anterolateral columns, the subject does not feel touch and pressure in the part of the body served by both pathways.

I am grateful to the many neurosurgeons who sent us patients for pain-relieving operations and to Dr Marion Smith and Ms Deacon for the figure.

1 Head $\mathrm{H}$, Thompson P. The grouping of afferent impulses within the spinal cord. Brain 1906;29:537-741.

2 Head H, Holmes G. Sensory disturbances from cerebral lesions. Brain 1911;34:102-254.

3 Head $H$. Sensation and the cerebral cortex. Brain 1918;41:57-253.

4 Head H. Studies in neurology, vol 2. Oxford University Press, and Hodder and Stoughton, London: 1920.

5 Nathan PW, Smith MC, Cook AW. Sensory effects in man of lesions of the posterior columns and of some other afferent pathways. Brain 1986;109:1003-41.

6 Goldscheider A. Psysiologie der Hautsinnesnerven. Leipzig, Barth: 1898:191.

7 White JC, Sweet WH. Pain and the Neurosurgeon. Springfield, USA: Charles C Thomas, 1969:687-9.

8 Foerster O. Symptomatologie der Erkrankungen des Rückenmarks und seiner Wurzeln. Vol 5. In: Bumke O, Foerster $O$, eds. Handbuch der Neurologie. Berlin: Springer, 1936:1-403.

9 Nathan PW. Improvement in cutaneous sensibility associated with relief of pain. J Neurol Neurosurg Psychiatry 1960;23:202-6.

10 Calne DB, Pallis CA. Vibratory sense: a critical review. Brain 1966;89:723-46.

11 Lockard BI, Kempe LG. Position sense in the lateral funiculus. Neurological Research 1988;10:81-6.

12 Noordenbos W, Wall PD. Diverse sensory functions with almost totally divided spinal cord. A case of spinal cord transection with preservation of part of one anterolateral quadrant. Pain 1971;2:185-95.

13 Wall PD, Noordenbos $W$. Sensory functions which remain in man after complete transection of dorsal columns. Brain 1977;100:641-53.

14 Lipschitz R, Block J. Stab wounds of the spinal cord. Lancet 1962;ii:169-72.

15 Peacock J, Shrosbree RD, Key AG. A review of 450 stab wounds of the spinal cord. South African Med J 1977;51:961-4.

16 Martin JP. The Basal Ganglia and Posture. London: Pitman Medical Publishing, 1967:32. 